\title{
Complete dislocation with burst fracture of the lower cervical spine. Case report
}

\author{
S Bhatia MS MCh, B S Sharma MS MCh, S N Mathuriya MS MCh, A Pathak MS \\ MCh, V K Khosla MS MCh
}

Department of Neurosurgery, Postgraduate Institute of Medical Education and Research, Chandigarh-160 012, India.

\begin{abstract}
A patient with a complete fracture dislocation of the C6 vertebra without any neurological deficit is presented. The absence of neurological changes in an area of the spinal canal which is almost completely filled with the spinal cord is remarkable. The mechanism of injury in this patient is believed to be hyperextension associated with significant axial loading. Hyperextension first ruptured the anterior and the posterior longitudinal ligaments and then injured the pedicles of C6. The associated axial loading resulted in a 'bursting' of the posterior elements, thereby providing room for the spinal cord to move dorsally with the avoidance of a major neurological deficit.
\end{abstract}

Keywords: burst fracture; lower cervical spine; hyperextension injury.

\section{Introduction}

Complete fracture dislocation in the lower cervical spine, with a saggital translation nearly equal to the anteroposterior width of the vertebral body almost always causes gross neurological deficits. The absence of any neurological deficit is very unusual, and there are only a few reports available in the literature. ${ }^{1,2}$ We present a patient with a complete fracture dislocation of $\mathrm{C} 6 / \mathrm{C} 7$ associated with burst fractures of the posterior elements of C5 and C6 and with no neurological deficit. The mechanism of injury is discussed and the literature is reviewed.

\section{Case report}

A 45 year old male fell from a roof top and remained unconscious for about an hour. $\mathrm{He}$ was brought to the hospital, able to walk without support and complaining of severe pain in the back of his neck and restriction of neck movements. Examination revealed a conscious individual with no external evidence of injury

Correspondence: Dr V K Khosla, Additional Professor \& Head, Department of Neurosurgery, P.G.I.M.E.R., Chandigarh, India-160 012. and marked restriction of neck movements in all directions. He had normal power in both the upper and the lower limbs. Deep tendon reflexes were normal. Abdominal reflexes were present and both plantar reflexes were flexor. There was no sensory deficit.

Plain xrays of the cervical spine revealed a complete fracture dislocation of $\mathrm{C} 6 / \mathrm{C} 7$ with fracture of the posterior elements of $\mathrm{C} 5$ and $\mathrm{C} 6$ (Fig 1). Computerized tomography followed the applications of skeletal traction with a $30 \mathrm{lb}$ weight. Both the laminae of C5 were fractured at their attachment to the articular pillar. The left pedicle of $\mathrm{C} 6$ was fractured at its junction with the body and the right lamina of C6 was fractured at its attachment with the articular pillar. The broken posterior elements were pushed back, opening up the spinal canal (Fig 2). Skeletal traction with $30 \mathrm{lb}$ of weight achieved a partial reduction. Significant distraction prevented the application of further weights (Fig 3). Posterior fusion with wire and bone was performed. Failure to achieve proper alignment necessitated excision of $\mathrm{C} 7$ body, fixation and bony fusion with an iliac crest graft with wire loops, by an anterolateral operative approach (Fig 4). The patient was discharged from hospital after the application of a Minerva jacket on the seventh postoperative day, without any neurological defect. 


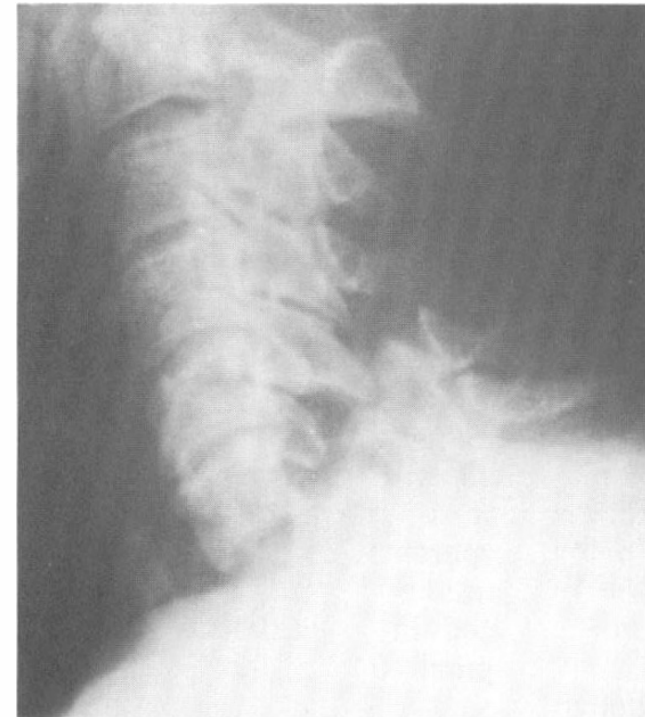

Figure 1 Lateral radiograph of the cervical spine showing the bursting of posterior elements of C5 \& C6 and facet dislocation of C6 on C7.

\section{Discussion}

The cervical spinal canal is almost completely filled by the spinal cord except for the uppermost part. It is also the most mobile part of the spine and the facet joints lie almost horizontally with the superior articular surfaces sloping medially. Severe traumatic hyperextension causes rupture of the intervertebral disc and annulus, separ-

(a)

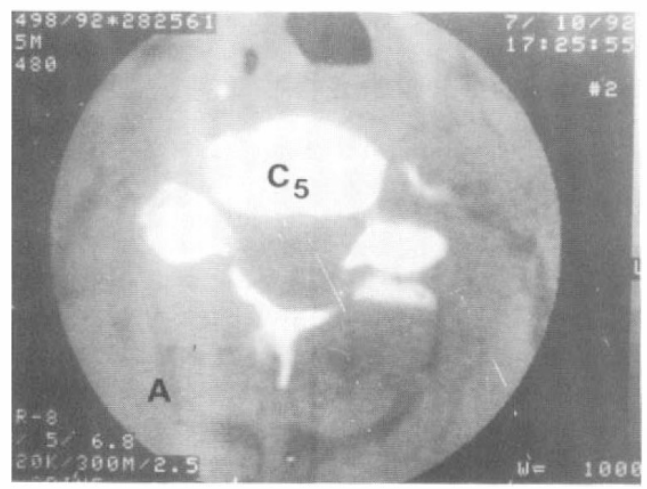

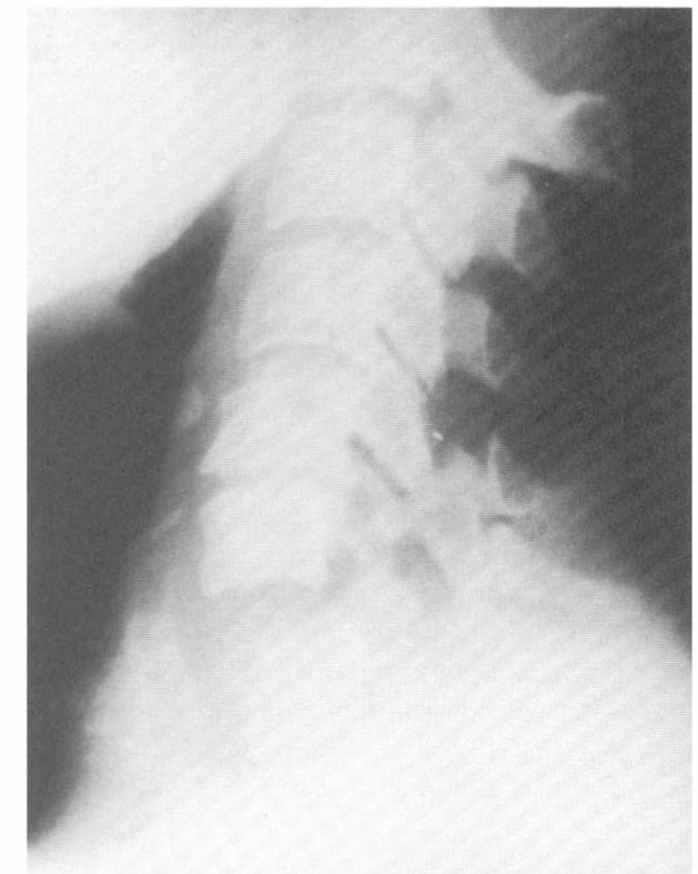

Figure 3 Lateral radiograph of the cervical spine showing reduction of the $\mathrm{C} 6-7$ dislocation and distraction.

ates the anterior longitudinal ligament from the vertebral end plates and can further rupture the posterior longitudinal ligament and cause pedicle fracture. ${ }^{3}$ Hyperextension is limited by the posterior elements coming in contact with each other but severe

(b)

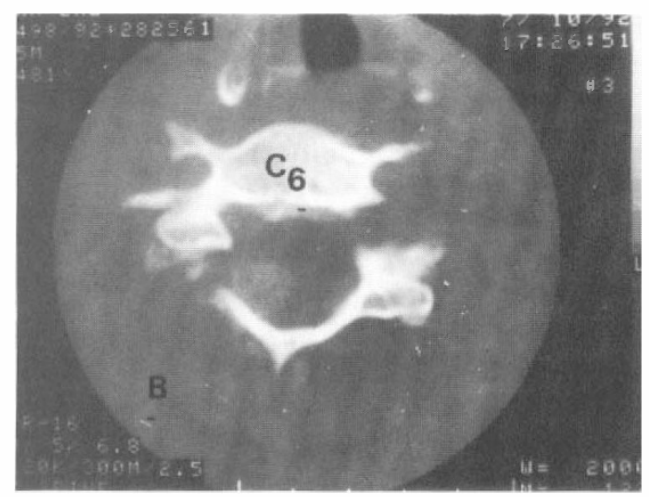

Figure 2 Axial CT cuts show the bursting of the spinal canal at the 5th (a) and 6th cervical vertebral (b) levels. 


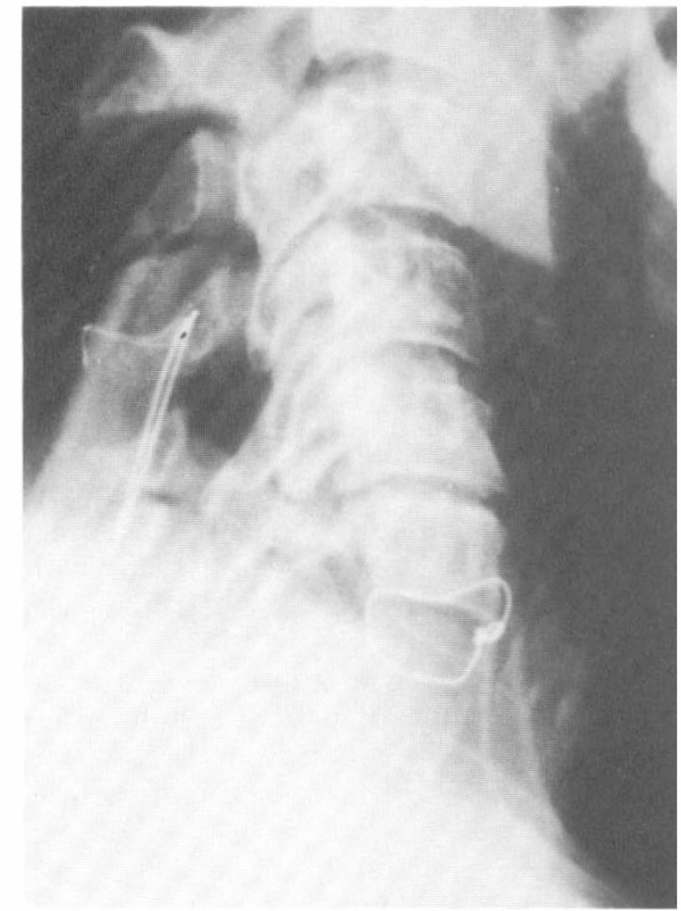

Figure 4 Postoperative radiograph showing the final result after the anterior and posterior fusion operations. hyperextension is known also to cause fracture of the posterior elements.

As the superior articular surfaces of the facets slope medially, significant axial loading tends to spread the broken posterior elements apart resulting in a burst fracture. Thus while hyperextension can account for the fracture-dislocation and the fractured posterior elements, we feel that it is the presence of significant axial loading which resulted in widening of the spinal canal and the avoidance of spinal cord damage in this patient. Both patients with complete fracture-dislocations and preserved neurological function reported to date have had $\mathrm{C} 6 / \mathrm{C} 7$ dislocations. This prediliction remains unexplained. Pitman et $a l^{1}$ reported a patient with a complete $\mathrm{C} 6 / \mathrm{C} 7$ dislocation who had incomplete neurological deficit which subsequently recovered. They considered that severe hyperextension was the mechanism of the injury in their patient. Baker et $a l^{2}$ also had a patient with a complete $\mathrm{C} 6 / \mathrm{C} 7$ dislocation and minimal neurological deficit. They also implicate hyperextension, with rupture of ligamentous structures and multiple posterior element fractures as the mechanism of injury.

\section{References}

1 Pitman MI, Pitman CA, Greenberg IM (1977) Complete dislocation of the cervical spine without neurological deficit. A case report. J Bone Joint Surg 59A: 134-137.

2 Baker RP, Grubb RL (1983) Complete fracture-dislocation of cervical spine without permanent neurological sequelae. Case report. J Neurosurg 58: 760-762.

3 White AA, Panjabi M (1978) Clinical Biomechanics of the Spine. J B Lippincott, Philadelphia: 158-160. 